\title{
Management of digoxin toxicity
}

\section{Matthew Pincus \\ Cardiologist \\ The Prince Charles Hospital \\ Brisbane}

\section{Key words}

arrhythmia, digoxin,

digoxin-specific antibody

fragments

Aust Prescr 2016;39:18-20

http://dx.doi.org/10.18773/ austprescr.2016.006

\section{SUMMARY}

Digoxin toxicity can emerge during long-term therapy as well as after an overdose. It can occur even when the serum digoxin concentration is within the therapeutic range.

Toxicity causes anorexia, nausea, vomiting and neurological symptoms. It can also trigger fatal arrhythmias. There is a range of indications for using digoxin-specific antibody fragments. The amount ingested and serum digoxin concentration help to determine the dose required, but are not essential.

Digoxin-specific antibody fragments are safe and effective in severe toxicity. Monitoring should continue after treatment because of the small risk of rebound toxicity.

Restarting therapy should take into account the indication for digoxin and any reasons why the concentration became toxic.

\section{Introduction}

Digoxin can be used to treat heart failure when symptoms remain despite the use of other drugs. It is also used for atrial fibrillation to reduce the ventricular rate. ${ }^{1}$ For heart failure, the recommended range for the serum digoxin concentration has been reduced over the past decade from $0.8-2.0$ nanogram $/ \mathrm{mL}$ to 0.5-0.9 nanogram $/ \mathrm{mL} .^{2}$ This is because of evidence of better outcomes at lower concentrations. ${ }^{3}$ Whether this range should also apply to patients with atrial fibrillation without heart failure is unknown.

\section{Incidence of toxicity}

Digoxin use has declined since the 1990s. ${ }^{4}$ While the overall incidence of toxicity per population has also declined, the incidence per treated patient may have remained unchanged. ${ }^{4,5}$ The Australian Institute of Health and Welfare records cardiac glycoside toxicity as the diagnosis on hospital discharge in 280, 233 and 139 patients in 1993-94, 2003-04 and 2011-12 respectively. ${ }^{6}$ Chronic toxicity is far more common than acute intoxication.?

\section{Digoxin pharmacology}

Digoxin increases intracellular calcium in myocardial cells indirectly, by inhibiting the sodium-potassium pump in the cell membrane. Increased intracellular calcium increases cardiac contractility, but also the risk of tachyarrhythmias. ${ }^{8}$ Inhibition of this pump causes the hyperkalaemia commonly seen in toxicity. Digoxin also causes an increase in vagal activity, reducing activity in the sinus node and prolonging conduction in the atrioventricular node.

After a dose of digoxin, distribution to the tissues takes several hours. This means that the serum digoxin concentration is inaccurate unless taken at least six hours after the last dose. Only a postdistribution measurement reflects the severity of intoxication and this is the measurement that can help when calculating the dose of digoxinspecific antibody. ${ }^{9}$ This applies in both acute and chronic poisoning.

The elimination of digoxin is mainly by renal clearance and is prolonged in patients with renal impairment. Transport by P-glycoprotein also contributes to elimination. ${ }^{8}$ Consequently, a higher serum digoxin concentration for a given dose occurs in patients with renal impairment, lower body weight and in those taking amiodarone, verapamil, macrolides, azole antifungals and cyclosporin, which inhibit P-glycoprotein transport. ${ }^{10}$

Although the serum digoxin concentration does predict the likelihood of toxicity, ${ }^{8,11}$ several conditions increase sensitivity to digoxin. They at least partly account for patients who develop toxicity when their serum digoxin concentration is within the therapeutic range." These conditions include hypokalaemia, hypomagnesaemia, hypercalcaemia, myocardial ischaemia, hypoxaemia and acid-base disturbances. ${ }^{10}$

\section{Clinical features}

The clinical features of toxicity are often nonspecific. They commonly include lethargy, confusion and gastrointestinal symptoms (anorexia, nausea, vomiting, diarrhoea and abdominal pain). ${ }^{10}$ Visual effects (blurred vision, colour disturbances, haloes and scotomas) are rarer in contemporary practice. ${ }^{8}$ Cardiac arrhythmias account for most deaths. ${ }^{9}$ 
Arrhythmias can occur even if the patient has no symptoms. Almost any arrhythmia can occur, with the exception of atrial tachyarrhythmias with a rapid ventricular response, ${ }^{8}$ because these usually require intact conduction in the atrioventricular node. Characteristic arrhythmias are those in which a tachyarrhythmia occurs simultaneously with sinus or atrioventricular node suppression, such as atrial and junctional tachycardia with atrioventricular block. However, sinus bradycardia, atrioventricular block and ventricular ectopy are more common. ${ }^{12}$ With severe toxicity, ventricular tachycardia (which may be bidirectional) and ventricular fibrillation can occur. 'Reverse tick' T-wave inversion is not a sign of toxicity.

\section{Treatment}

There are no evidence-based guidelines for the management of mild to moderate toxicity so there is a wide variation in treatment. ${ }^{13}$ Severe toxicity requires hospital admission and consideration of the need for digoxin-specific antibody fragments. Although digoxin-specific antibody fragments are safe and effective, randomised trials have not been performed.

The antibody fragments form complexes with the digoxin molecules. These complexes are then excreted in the urine.

\section{Indications for digoxin-specific antibody fragments}

The indications for digoxin-specific antibody fragments are inconsistent. Four contemporary sources ${ }^{1,9,14,15}$ recommend administration for strongly suspected or known digoxin toxicity with:

- life-threatening arrhythmia

- cardiac arrest

- potassium $>5.0 \mathrm{mmol} / \mathrm{L}$ (significant hyperkalaemia is a strong indication for treatment because of its association with a poor prognosis if digoxinspecific antibody fragments are not given ${ }^{16}$ ).

However, the same sources vary in their recommendations for administration when there is:

- acute ingestion of $>10 \mathrm{mg}$ in adults or $>4 \mathrm{mg}$ in children

- evidence of end-organ dysfunction

- moderate to severe gastrointestinal symptoms

- serum digoxin concentration $>12$ nanogram $/ \mathrm{mL}$

- significant clinical features of digoxin toxicity with serum digoxin concentration $>1.6$ nanogram $/ \mathrm{mL}$.

Such disagreements over when to use digoxinspecific antibody fragments arise from cost-benefit, not harm-benefit, considerations. The cost is roughly $\$ 1000$ per ampoule and several ampoules may be used. However, economic arguments have been made for their use in non-life-threatening toxicity, as the duration of hospitalisation may be reduced..$^{17}$

\section{Dose and administration}

Only one formulation is available in Australia. Each ampoule contains $40 \mathrm{mg}$ of powdered digoxinspecific antibody and is reconstituted with $4 \mathrm{~mL}$ of water. This can be given as a slow push in cardiac arrest, but otherwise the total dose is diluted further with normal saline and infused over 30 minutes.

The response begins about 20 minutes (range 0-60 $\mathrm{min}$ ) after administration. A complete response occurs in 90 minutes (range 30-360 min). ${ }^{14}$

Conventional dosing protocols aim to neutralise total body digoxin completely. The total dose is usually expressed in vials. It depends on whether the postdistribution serum digoxin concentration is known, the amount ingested is known, or neither is known..$^{15}$

\section{Known digoxin concentration}

If the post-distribution concentration is known (in either acute or chronic ingestion), knowing the amount ingested is unnecessary. The dose is:

number of vials $=$ post-distribution serum digoxin concentration (nanogram $/ \mathrm{mL}$ ) x weight $(\mathrm{kg}) / 100$ (multiply by 0.78 if SI units are used for postdistribution serum digoxin concentration).

\section{Known amount ingested}

If the quantity of digoxin ingested is known, but the post-distribution serum digoxin concentration is unknown, the dose is:

number of vials = amount ingested $(\mathrm{mg}) \times 2 \times 0.7$

(0.7 is the bioavailability of digoxin tablets supplied in Australia).

\section{Unknown data}

When neither the post-distribution serum digoxin concentration nor the amount ingested is known, use empiric dosing. Repeat in $\mathbf{3 0}$ minutes if the response is inadequate. The dose is:

for adults and children greater than $20 \mathrm{~kg}$

- five vials if haemodynamically stable

- 10 vials if unstable

for children less than $20 \mathrm{~kg}$

- one vial.

\section{Other regimens}

Some authors have argued for modification of the calculated doses to be given as an initial half dose followed by either further doses as required ${ }^{18}$ or an infusion. ${ }^{19}$ These suggestions follow from the view that full dosing is unnecessary to achieve tolerable 


\section{SELF-TEST} QUESTIONS

True or false?

5. Digoxin toxicity can occur when the serum digoxin concentration is within the reference range.

6. Concentrations of serum digoxin should be measured within six hours of a dose.

Answers on page 27 concentrations of digoxin and may be undesirable in patients who need digoxin. 18,20 There are also concerns that significant amounts of digoxin-specific antibody fragments may be eliminated before full removal of digoxin from tissue stores. ${ }^{19}$ Furthermore, in practice many hospitals will not stock sufficient ampoules for the full calculated dose. In this case specialist toxicological advice should be sought on the adequacy of modified dosing.

\section{Precautions and adverse effects}

Hypomagnesaemia and, more importantly, hypokalaemia (common with diuretic use) should be corrected before or during administration because digoxin-specific antibody fragments will further lower potassium. ${ }^{14}$ Hypokalaemia occurs as a result of treatment in about $4 \%$ of patients. ${ }^{21}$ Serum potassium should be frequently monitored. ${ }^{14}$

'Rebound' toxicity' is the reappearance of toxicity after an initial response to digoxin-specific antibody fragments. This occurs in about $2 \%$ of patients given a full neutralising dose. ${ }^{21}$ It can develop 12-24 hours after treatment, but up to 10 days later in patients with renal failure. ${ }^{14}$ Serum digoxin concentration is of no use in diagnosis, because it measures the digoxin in the complexes with antibody fragments as well as unbound digoxin. The concentration therefore rises many fold after digoxin-specific antibody fragments are given even in the absence of rebound toxicity. ${ }^{22}$

Heart failure or atrial fibrillation with rapid ventricular response (presumed re-emergent due to removal of digoxin effect) occurs in up to $3 \%$ of patients. ${ }^{14}$ Allergic reactions occur in about $1 \%$ of infusions. ${ }^{21}$

\section{Other treatments}

Other treatments for severe toxicity should be seen as temporising or adjunct measures, rather than alternatives to digoxin-specific antibody fragments. Activated charcoal ${ }^{23}$ can be used in patients who present within two hours of acute ingestion.

Hyperkalaemia will improve with giving digoxinspecific antibody fragments, and conventional treatments such as calcium will generally be unnecessary or harmful. ${ }^{15}$ If the patient has severe hypokalaemia and digoxin toxicity, it is important to correct the serum potassium.
Lignocaine $^{8}$ can be used for ventricular tachyarrhythmias and atropine ${ }^{15}$ for bradyarrhythmias. Cardioversion, which can result in ventricular fibrillation, should be avoided.

In cardiac arrest, resuscitation efforts should be continued for at least 30 minutes after giving digoxinspecific antibody fragments.

\section{Restarting digoxin}

When considering restarting digoxin, first determine whether the patient's indication for use and target serum digoxin concentration were consistent with current guidelines, as these have changed markedly over the past couple of decades. Digoxin can be resumed after adjusting the dose for changes in target serum digoxin concentration, renal function and weight if necessary. This should be delayed until all the digoxin-specific antibody fragments have been cleared, which will take up to a week, but far longer in the presence of renal dysfunction. ${ }^{18,22}$

\section{Conclusion}

Digoxin toxicity has declined, possibly as a result of a decreasing use and a reduced recommended therapeutic range. It can occur when serum digoxin concentration is within the therapeutic range and, as the presenting features are usually non-specific, the diagnosis can be difficult.

Digoxin-specific antibody fragments are used when there is a risk of a life-threatening arrhythmia. The decision to use digoxin-specific antibody fragments is not dependent on knowledge of the serum digoxin concentration or the amount of digoxin ingested, but when either of these is known they should be used to calculate the dose. Further research is needed into optimal dosing protocols and whether digoxin-specific antibody fragments can be cost-effectively used for non-life-threatening toxicity. $<$

Dr Pincus has been an investigator in trials sponsored by Bristol-Myers Squibb, GlaxoSmithKline, AstraZeneca, Sanofi, Servier, Amgen and Janssen. He received financial assistance for conference attendance from Eli Lilly, Bayer, Boehringer Ingelheim, Bristol-Myers Squibb and Pfizer. Digoxin and the only available digoxin-specific Fab (DigiFab) are not supplied by these companies. 
1. Cardiovascular. Version 6. In: eTG complete [Internet]. Melbourne: Therapeutic Guidelines Limited; 2014. http://www.tg.org.au/index.php?sectionid=71 [cited 2016 Jan 4]

2. Yancy CW, Jessup M, Bozkurt B, Butler J, Casey DE Jr, Drazner MH, et al.; American College of Cardiology Foundation; American Heart Association Task Force on Practice Guidelines. 2013 ACCF/AHA guideline for the management of heart failure: a report of the American College of Cardiology Foundation/American Heart Association Task Force on Practice Guidelines. J Am Coll Cardiol 2013;62:e147-239. http://dx.doi.org/ 10.1016/j.jacc.2013.05.019

3. Rathore SS, Curtis JP, Wang Y, Bristow MR, Krumholz HM. Association of serum digoxin concentration and outcomes in patients with heart failure. JAMA 2003;289:871-8. http://dx.doi.org/10.1001/jama.289.7.871

4. Haynes K, Heitjan D, Kanetsky P, Hennessy S. Declining public health burden of digoxin toxicity from 1991 to 2004. Clin Pharmacol Ther 2008;84:90-4. http://dx.doi.org/ 10.1038/sj.clpt.6100458

5. Schmiedl S, Rottenkolber M, Szymanski J, Hasford J, Thuermann PA. Declining public health burden of digoxin toxicity: decreased use or safer prescribing? Clin Pharmacol Ther 2009;85:143-4. http://dx.doi.org/10.1038/ clpt.2008.252

6. Australian Institute of Health and Welfare. Principal diagnosis data cubes. 2013. www.aihw.gov.au/hospitals-data/ principal-diagnosis-data-cubes [cited 2016 Jan 4]

7. Lapostolle F, Borron SW, Verdier C, Arnaud F, Couvreur J, Mégarbane $\mathrm{B}$, et al. Assessment of digoxin antibody use in patients with elevated serum digoxin following chronic or acute exposure. Intensive Care Med 2008;34:1448-53. http://dx.doi.org/10.1007/s00134-008-1092-x

8. Bauman JL, Didomenico RJ, Galanter WL. Mechanisms, manifestations, and management of digoxin toxicity in the modern era. Am J Cardiovasc Drugs 2006;6:77-86. http://dx.doi.org/10.2165/00129784-200606020-00002

9. Kanji S, MacLean RD. Cardiac glycoside toxicity: more than 200 years and counting. Crit Care Clin 2012;28:527-35. http://dx.doi.org/10.1016/j.ccc.2012.07.005

10. Yang EH, Shah S, Criley JM. Digitalis toxicity: a fading but crucial complication to recognize. Am J Med 2012;125:337-43. http://dx.doi.org/10.1016/j.amjmed.2011.09.019

11. Abad-Santos F, Carcas AJ, Ibáñez C, Frías J. Digoxin level and clinical manifestations as determinants in the diagnosis of digoxin toxicity. Ther Drug Monit 2000;22:163-8. http://dx.doi.org/10.1097/00007691-200004000-00004
12. Williamson KM, Thrasher KA, Fulton KB, LaPointe NM, Dunham GD, Cooper AA, et al. Digoxin toxicity: an evaluation in current clinical practice. Arch Intern Med 1998;158:2444-9. http://dx.doi.org/10.1001/archinte.158.22.2444

13. Kirrane BM, Olmedo RE, Nelson LS, Mercurio-Zappala M, Howland MA, Hoffman RS. Inconsistent approach to the treatment of chronic digoxin toxicity in the United States. Hum Exp Toxicol 2009;28:285-92. http://dx.doi.org/ $10.1177 / 0960327109105405$

14. Nelson L, Goldfrank LR. Goldfrank’s Toxicologic emergencies. 9th ed. New York: McGraw-Hill Medical; 2011.

15. Murray L, Daley F, Little M, Cadogan M. Toxicology handbook. 2nd ed. Sydney: Elsevier; 2011.

16. Bismuth C, Gaultier M, Conso F, Efthymiou ML. Hyperkalemia in acute digitalis poisoning: prognostic significance and therapeutic implications. Clin Toxicol 1973;6:153-62. http://dx.doi.org/10.3109/15563657308990513

17. Gandhi AJ, Vlasses PH, Morton DJ, Bauman JL. Economic impact of digoxin toxicity. Pharmacoeconomics 1997:12:175-81. http://dx.doi.org/10.2165/00019053-199712020-00007

18. Bateman DN. Digoxin-specific antibody fragments: how much and when? Toxicol Rev 2004;23:135-43. http://dx.doi.org/10.2165/00139709-200423030-00001

19. Eyer F, Steimer W, Müller C, Zilker T. Free and total digoxin in serum during treatment of acute digoxin poisoning with Fab fragments: case study. Am J Crit Care 2010;19:391-87. http://dx.doi.org/10.4037/ajcc2009227

20. Chan BS, Buckley NA. Digoxin-specific antibody fragments in the treatment of digoxin toxicity. Clin Toxicol (Phila) 2014;52:824-36. http://dx.doi.org/ 10.3109/15563650.2014.943907

21. Hickey AR, Wenger TL, Carpenter VP, Tilson HH, Hlatky MA, Furberg CD, et al. Digoxin Immune Fab therapy in the management of digitalis intoxication: safety and efficacy results of an observational surveillance study. J Am Coll Cardiol 1991;17:590-8. http://dx.doi.org/10.1016/ S0735-1097(10)80170-6

22. Ujhelyi MR, Robert S. Pharmacokinetic aspects of digoxinspecific Fab therapy in the management of digitalis toxicity. Clin Pharmacokinet 1995;28:483-93. http://dx.doi.org/ 10.2165/00003088-199528060-00006

23. Lalonde RL, Deshpande R, Hamilton PP, McLean WM, Greenway DC. Acceleration of digoxin clearance by activated charcoal. Clin Pharmacol Ther 1985;37:367-71. http://dx.doi.org/10.1038/clpt.1985.55 